\section{Research Square}

Preprints are preliminary reports that have not undergone peer review.

They should not be considered conclusive, used to inform clinical practice, or referenced by the media as validated information.

\title{
Identification of Candidate Genes Associated with Bacterial and Viral Infections in Wild Boars Hunted in Tuscany (Italy)
}

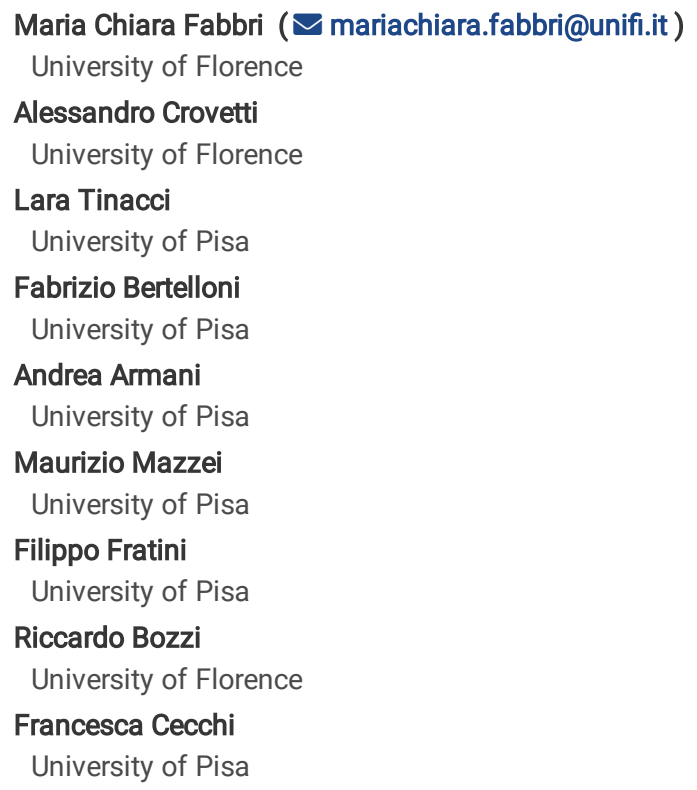




\section{Abstract}

Wild boar (Sus scrofa L.) is one of the large mammals most spread worldwide, highly adaptable, and its population has rapidly increased in many areas in Europe. Central Italy, as well as Tuscany, is an area particularly suitable for wild boar. Wild boars are potential hosts for different etiological agents, such as Brucella spp., Leptospira spp. and Pseudorabies virus and can contribute to maintain and/or to disseminate some bacterial or viral pathogens to humans and domestic animals, above all-in free-range farms. In order to identify hypothetical genomic regions associated with these infection diseases, 96 samples of wild boars hunted in Tuscany during the 2018-2019 and 2019-2020 hunting seasons were considered. Diagnosis was achieved by serological tests and 42 Pseudorabies, 31 Leptospira and 15 Brucella positive animals were identified. All animals were genotyped with Geneseek Genomic Profiler Porcine HD (70k) and a genome-wide scan was then performed. Significant markers were highlighted for Pseudorabies (two SNPs), Brucella (seven SNPs), and Leptospira (four SNPs) and they were located within, or nearby, 29 annotated genes on chromosome 6, 9, 12, 13, 14 and 18. Eight genes are implicated in viral (SEC14L1, JMJD6, SRSF2, TMPRSS2, MX1, MX2) or bacterial (COL8A1, SPIRE1) infections, seven genes (MFSD11, METTL23, CTTNBP2, BACE2, IMPA2, MPPE1 and GNAL) are involved in mental disorders and one gene (MGAT5B) is related to the Golgi complex. Results presented here provide interesting starting points for future research, validation studies and fine mapping of candidate genes involved in bacterial and viral infections in wild boar.

\section{Introduction}

The wild boar (Sus scrofa L.) is widely distributed throughout Eurasia from Europe to the Far East, including SouthEast Asia, and extending to North Africa ${ }^{1}$, and is considered the second most abundant ungulate species in Europe ${ }^{2}$.

In Italy, the wild boar population is widely diffused ${ }^{3}$, reaching high-density levels in specific areas ${ }^{4}$. Central Italy, and in particular Tuscany, are suited to the wild boar. This is evidenced by the high number of animals hunted in this area ${ }^{3-5}$.

The high density of wild boar in a particular area is a serious problem for the agricultural economy, causing extensive damage to croplands ${ }^{6}$ and may represents a severe hazard for both animals and human health.

In fact, it is known that wild boar can be the host for different etiological agents, thus contributing to maintaining and/or disseminating important zoonotic diseases ${ }^{7}$, as well as leptospirosis and brucellosis. Other diseases are not zoonosis but have a large economic impact on the swine industry, such as the Pseudorabies (PrV) or Aujeszky's disease.

Brucella is a zoonotic Gram-negative bacterium. Among the different species, $B$. abortus, $B$. suis, and rarely, $B$. melitensis can infect swine as well as wild boar (Sus scrofa) ${ }^{8-10}$. Tuscany, as many other Italian regions, is free from bovine and ovine brucellosis from several years thanks to the progress of the eradication plan implemented throughout the country since 1992 and 1994 (D.M. 2/7/92 n. 453; D.M. 27/8/94 n. 651; EFSA 2017). B. suis biovars 1 and 3 are rarely reported in Europe, while $B$. suis biovar 2 (bv. 2) is largely diffused in East Europe, and it was recently introduced in Italy where it was isolated from domestic pigs and wild boar $8,10,11$. Wild boar represents one of the main reservoirs of $B$. suis bv. 2 , which is responsible for reproductive disorders such as, infertility, abortion, stillbirths, decreased litter size, weak piglets, orchitis and epididymitis in males, and focal abscess formation ${ }^{10}$. Recently, $B$. suis bv. 2 has been detected also in cows, in which seroconversion was detected without the presence of clinical signs ${ }^{12,13}$. Human infections by this serovar are rarely reported ${ }^{11}$.

Leptospirosis represents a re-emerging zoonotic worldwide disease; it is caused by Leptospira spp., a Gram-negative spirochetal bacterium. The genus Leptospira is traditionally divided into more than 260 antigenically-different serovars, at present classified as pathogenic, intermediate, and saprophytic, with different levels of pathogenicity for animals and humans ${ }^{\mathbf{1 4}, 15}$. Swine are the reservoir host for some serovars (Pomona, Tarassovi, and Bratislava), but it is not excluded that it could be infected by many others serovars ${ }^{16}$. Wild boar, due to their natural behaviour and in relation to the geographical area where they live, are often infected by several serovars such as Icterohaemorrhagiae, Grippotyphosa and Canicola ${ }^{17-19}$. As demonstrated by several studies, North Central Italy, and in particular Tuscany, presents some environmental and geographic features that promote the Leptospira spread; consequently, wild boar and feral pig living in contact with domestic animals and humans, represent one of the most important Leptospira reservoir among wildlife. For this reason, wild boar is considered an "indicator" of leptospirosis in those area where many different species are forced to co-exist ${ }^{20-}$ 22 .

Pseudorabies or Aujeszky's disease (PrV) is caused by Suid herpesvirus 1 which belongs to the Herpesviridae family, subfamily Alphaherpesvirinae, genus Varicellovirus ${ }^{23}$. This virus, as the other members of the afore mentioned family, is enveloped with a double-stranded DNA genome. Although domestic swine and wild boar represent the natural host of $\mathrm{PrV}$, the virus can also infect numerous wild and domestic mammals including ruminants, carnivores, and rodents 24,25 .

Pseudorabies virus circulates in domestic swine and wild boar (Sus scrofa) populations in several countries ${ }^{26}$. The PrV wild boar seroprevalence in Europe ranges from $4-66 \%$, representing a risk of infection for domestic swine and other susceptible animals ${ }^{26-29}$. Consequently, the role of wild boars in the epidemiology of the Pseudorabies is of primary importance, because a serious threat to the completion of the European Community eradication program. 
Further knowledge on alternative methods to control the spread of the disease should therefore be investigated. The use of disease-resistant livestock breeds that reduce infection pressure with a decreased incidence of disease is therefore of considerable importance ${ }^{30}$.

Virulence of pathogens and susceptibility of wildlife species to disease are influenced by attributes of the host and the pathogen. Discovering the factors that determine host susceptibility/resistance to disease contributes to prevent diseases in both human and domestic animals and improve "global health". A wide range of genetic variations in disease resistance has been observed in swine regarding different viral, bacterial, and parasitic diseases ${ }^{30}$.

Previous studies have reported that genetic diversity of individuals and populations of wildlife, at both neutral loci and functional genes, are related to disease tolerance or resistance. Indeed, high levels of inbreeding ${ }^{31,32}$ with a consequent heterozygosity reduction at neutral microsatellite markers can increase susceptibility to disease in wildlife $\mathrm{e}^{33-35}$. Acevedo-Whitehouse et al. (2005) ${ }^{36}$ highlighted that a higher genetic heterozygosity was associated with lower probability of infection of bovine tuberculosis in wild boar.

The major histocompatibility complex (MHC), a highly polymorphic family of vertebrate genes involved in initiation and regulation of the immune response, has been the target of considerable investigation of disease resistance and tolerance in wildlife ${ }^{37,38}$. Recent advances in genome sequencing, and particularly in the development of high-density single nucleotide polymorphism (SNPs) arrays, have improved genome-wide screening and, therefore, our ability to detect disease-associated genes ${ }^{39}$ and to identify the genetic control of disease resilience ${ }^{40}$. For example, in wild sus scrofa, Queirós et al. $(2018)^{39}$ found genes (i.e. LOC102164072, BDNF/NT-3, NTRK2, CDH8, IGSF21) as candidates for host genetic susceptibility to tuberculosis. Recently, Uemoto et al. (2021) ${ }^{41}$ conducted genome-wide association studies for production, respiratory disease, and immune-related traits in Landrace pigs.

Given the importance of these pathogens in animals and as a potential risk factor for human diseases, our study is one of the first attempts to identify genomic regions associated with infections from Pseudorabies virus, Brucella spp. and Leptospira spp. in wild boar.

\section{Results}

Table 1: Total number of SNPs before (pre-QC) and post quality control (post-QC) for each autosomal chromosome.

\begin{tabular}{llll} 
Chromosome & Total Markers pre-QC & Total Markers post-QC & $\%$ Markers \\
\hline 1 & 5926 & 4054 & 9.55 \\
\hline 2 & 4141 & 2546 & 6.00 \\
\hline 3 & 3575 & 2600 & 6.13 \\
\hline 4 & 3807 & 2626 & 6.19 \\
\hline 5 & 3009 & 2103 & 4.95 \\
\hline 6 & 4360 & 2870 & 6.76 \\
\hline 7 & 3943 & 2823 & 6.66 \\
\hline 8 & 3533 & 2376 & 5.60 \\
\hline 9 & 3856 & 2730 & 6.43 \\
\hline 10 & 2873 & 1967 & 4.63 \\
\hline 11 & 2344 & 1623 & 3.82 \\
\hline 12 & 2513 & 1526 & 3.59 \\
\hline 13 & 4435 & 3088 & 7.28 \\
\hline 14 & 4087 & 2556 & 6.02 \\
\hline 15 & 3607 & 2534 & 5.97 \\
\hline 16 & 2386 & 1748 & 4.12 \\
\hline 17 & 2178 & 1350 & 3.18 \\
\hline 18 & 1757 & 1311 & \\
\hline
\end{tabular}

Table 2 reports the prevalence of positive samples over the total of 96 for Pseudorabies, Brucella and Leptospira. Positivity to two etiological agents was detected only in $5 / 96$ samples $(5.21 \%$; $95 \% \mathrm{Cl}$ : $2.00-8.42 \%)$. Ten were the negative samples.

Table 2: Number of positive animals and prevalence of Pseudorabies, Brucella and Leptospira and in the 96 animals sampled in Tuscany. 


\begin{tabular}{lllll} 
Infection & Total analysed animals & Positive animals & Prevalence (\%) & $95 \% \mathrm{Cl}$ \\
\hline Pseudorabies & 96 & 42 & 48.9 & $36.58-50.92$ \\
\hline Brucella & 96 & 15 & 15.6 & $10.28-20.37$ \\
\hline Leptospira & 96 & 31 & 32.3 & $25.54-39.05$
\end{tabular}

Genome-wide scan was performed, and 13 significant SNPs were identified, as shown in table 3.

Table 3: List of significant SNPs identified for each disease. The SNP name, the position information in Sus scrofa Assembly 11.1, the p-value, the type of variant, and the list of the candidate genes in the regions flanking the significant markers $( \pm 250,000$ nucleotides $)$ are reported.

\begin{tabular}{|c|c|c|c|c|c|c|c|c|c|}
\hline \multicolumn{2}{|l|}{ Infection } & Name & Chr & Position & Pvalue & $\begin{array}{l}\text { Type of } \\
\text { Variant }\end{array}$ & Within & Upstream & Downstream \\
\hline \multirow[t]{2}{*}{ Pseudorabies } & ASGA0084173 & rs81341734 & 12 & 4612583 & $\begin{array}{l}4,12 \mathrm{E}- \\
05\end{array}$ & $\begin{array}{l}\text { intergenic } \\
\text { variant }\end{array}$ & - & $\begin{array}{l}\text { SEC14L 1, } \\
\text { MGAT5B }\end{array}$ & $\begin{array}{l}\text { JMJD6, } \\
\text { MXRA7, } \\
\text { MFSD11, } \\
\text { METTL23, } \\
\text { SRSF2 }\end{array}$ \\
\hline & WU_10.2_18_30218795 & rs339406967 & 18 & 28399958 & $\begin{array}{l}3,04 \mathrm{E}- \\
05\end{array}$ & $\begin{array}{l}\text { intron } \\
\text { variant }\end{array}$ & CTTNBP2 & - & CFTR \\
\hline \multirow[t]{7}{*}{ Brucella } & MARC0040908 & rs81232015 & 9 & 58693183 & $\begin{array}{l}1,55 \mathrm{E}- \\
05\end{array}$ & $\begin{array}{l}\text { intron } \\
\text { variant }\end{array}$ & NTM & - & - \\
\hline & MARC0029225 & rs81224033 & 9 & 58592360 & $\begin{array}{l}1,79 \mathrm{E}- \\
05\end{array}$ & $\begin{array}{l}\text { intron } \\
\text { variant }\end{array}$ & NTM & - & - \\
\hline & ALGA0073505 & rs80987534 & 13 & 190711065 & $\begin{array}{l}1,86 \mathrm{E}- \\
05\end{array}$ & $\begin{array}{l}\text { intergenic } \\
\text { variant }\end{array}$ & - & - & - \\
\hline & WU_10.2_13_200912860 & rs319979903 & 13 & 190770452 & $\begin{array}{l}1,86 \mathrm{E}- \\
05\end{array}$ & $\begin{array}{l}\text { intergenic } \\
\text { variant }\end{array}$ & - & - & - \\
\hline & ASGA0060211 & rs81443008 & 13 & 204883958 & $\begin{array}{l}2,44 \mathrm{E}- \\
05\end{array}$ & $\begin{array}{l}\text { intron } \\
\text { variant }\end{array}$ & TMPRSS2 & $\begin{array}{l}B A C E 2, \\
F A M 3 B \\
M X 1, M X 2\end{array}$ & RIPK4 \\
\hline & MARC0024545 & rs80808271 & 13 & 159240192 & $\begin{array}{l}4,78 \mathrm{E}- \\
05\end{array}$ & $\begin{array}{l}\text { intron } \\
\text { variant }\end{array}$ & COL8A1 & $\begin{array}{l}\text { CMSS1, } \\
\text { FILIP1L }\end{array}$ & - \\
\hline & ALGA0072626 & rs80896010 & 13 & 159213442 & $\begin{array}{l}4,78 \mathrm{E}- \\
05\end{array}$ & $\begin{array}{l}\text { downstream } \\
\text { gene variant }\end{array}$ & - & $\begin{array}{l}\text { CMSS1, } \\
\text { FILIP1L }\end{array}$ & COL8A1 \\
\hline \multirow[t]{4}{*}{ Leptospira } & H3GA0053117 & rs81338390 & 6 & 97242874 & $\begin{array}{l}1,12 \mathrm{E}- \\
05\end{array}$ & $\begin{array}{l}\text { upstream } \\
\text { gene variant }\end{array}$ & - & $\begin{array}{l}\text { SPIRE1, } \\
\text { PRELID3A, } \\
\text { AFG3L2, } \\
\text { TUBB6 }\end{array}$ & $\begin{array}{l}\text { CIDEA, } \\
\text { IMPA2, } \\
\text { MPPE1, } \\
\text { CHMP1B, } \\
\text { GNAL, } \\
\text { TRNAG- UCC }\end{array}$ \\
\hline & WU 10.21310381840 & rs324503493 & 13 & 9111717 & $\begin{array}{l}2,05 \mathrm{E}- \\
05\end{array}$ & $\begin{array}{l}\text { upstream } \\
\text { gene variant }\end{array}$ & ZNF385D & - & - \\
\hline & H3GA0042130 & rs80982803 & 14 & 114457304 & $\begin{array}{l}1,99 \mathrm{E}- \\
05\end{array}$ & $\begin{array}{l}\text { intron } \\
\text { variant }\end{array}$ & NEURL 1 & $\begin{array}{l}\text { INA, } \\
\text { PCGF6, } \\
\text { TAF5, } \\
\text { MIR1307, } \\
\text { USMG5, } \\
\text { PDCD11, } \\
\text { CALHM3 }\end{array}$ & $S H 3 P X D 2 A$ \\
\hline & ASGA0066225 & rs80944071 & 14 & 114471571 & $\begin{array}{l}1,99 \mathrm{E}- \\
05\end{array}$ & $\begin{array}{l}\text { intron } \\
\text { variant }\end{array}$ & NEURL 1 & $\begin{array}{l}\text { INA, } \\
\text { PCGF6, } \\
\text { TAF5, } \\
\text { MIR1307, } \\
\text { USMG5, } \\
\text { PDCD11, } \\
\text { CALHM3 }\end{array}$ & $S H 3 P X D 2 A$ \\
\hline
\end{tabular}

Two SNPs found a significant association with the Pseudorabies as described in Figure 1.

ASGA0084173 is located on chromosome 12, with SEC14L 1 and MGAT5B genes located upstream and JMJD6, MXRA7, MFSD11, METTL23, SRSF2 genes downstream; WU_10.2_18_30218795 is located on chromosome 18, within CTTNBP2 gene and upstream to CFTR gene.

A higher number of SNPs were identified analysing Brucella infection (Figure 2), precisely, seven SNPs are found significantly associated with this disease. 
Both MARC0040908 and MARC0029225 markers are on chromosome 9 within NTM gene. 250 Kbp upstream and 250 Kbp downstream of the aforementioned SNPs no genes are found (Table 3).

The other five significant SNPs are located on chromosome 13: two of them, namely, MARC0024545 and ALGA0072626, are situated in a close region, sharing CMSS1 and FILIP1L genes, which are found upstream to the two SNPs. MARC0024545 is an intron variant because within COL8A1, while ALGA0072626 is downstream to the aforementioned gene. ALGA0073505 and WU_10.2_13_200912860 markers are in a genomic region where no characterized genes are present. ASGA0060211 is classified from VeP database as intron variant because it is positioned on TMPRSS2 gene. BACE2, $F A M 3 B, M X 1$ and $M X 2$ genes are upstream and RIPK4 is downstream to the SNPs.

Figure 3 described the four significant associated SNPs for Leptospira.

The H3GA005311 is located on chromosome 6, in a genomic window rich of genes: SPIRE1, PRELID3A, AFG3L2 and TUBB6 are upstream and CIDEA, IMPA2, MPPE1, CHMP1B, GNAL and TRNAG-UCC are downstream of this marker. WU_10.2_13_10381840 has been found within ZNF385D gene. H3GA0042130 and ASGA0066225 are close to each other, at less than $15 \mathrm{Kbp}$. Both are located on NEURL1 gene, with INA, PCGF6, TAF5, MIR1307, USMG5, PDCD11, CALHM3 upstream and SH3PXD2A downstream genes.

STRING software was used to analyse the possible interactions among proteins encoded by identified genes. Figure 4 showed the results for each infection.

Three of the nine genes for Pseudorabies infection are linked (JMJD6, MGAT5B and METTL23, Figure 4a). Brucella phenotype showed the greater interactions among genes: two clusters are identified, the first between FILIP1L and CMSS1, and the second one among MX1, MX2, RIPK4, TMPRSS2, $B A C E 2$ and $F A M 3 B$ genes (Figure $4 \mathrm{~b}$ ). Although Leptospira was the infection with more genes found in the significant genomic window, a few genes are linked to each other (IMPA2, MPPE1, and GNAL - TAF5 and USMG5, Figure 4c).

Using the PANTHER software, it was possible to summarize the biological processes and molecular functions in which the identified candidate genes are involved (Table 4); for all the infections, the functional genes were enriched in "GO: 0065007, biological regulation", "GO: 0009987, cellular process", "GO: 0051179, localization" and "GO: 0008152, metabolic process". Furthermore, the functional genes of Leptospira were enriched in many other processes including "GO:0000003, reproduction" and "GO: 0022414, reproductive process". More molecular functions were detected for genes involved in Leptospira infection than for Pseudorabies and Brucella infections.

Table 4: Biological process and molecular function Gene Ontology (GO) terms enrichment analysis results.

\begin{tabular}{|c|c|c|}
\hline Infection & Biological Process GO Terms & Molecular Function GO Terms \\
\hline Pseudorabies & $\begin{array}{l}\text { GO: 0065007, biological regulation; GO: 0009987, cellular process; GO: } 0051179 \text {, } \\
\text { localization; GO: 0008152, metabolic process }\end{array}$ & $\begin{array}{l}\text { GO:000548, binding; G0:0003824, } \\
\text { catalytic activity; GO:0005215, } \\
\text { transporter activity }\end{array}$ \\
\hline Brucella & $\begin{array}{l}\text { GO: 0065007, biological regulation; GO: 0009987, cellular process; GO: } 0051179 \text {, } \\
\text { localization; GO: 0008152, metabolic process }\end{array}$ & $\begin{array}{l}\text { GO:000548, binding; G0:0003824, } \\
\text { catalytic activity; GO:0005215, } \\
\text { transporter activity }\end{array}$ \\
\hline Leptospira & $\begin{array}{l}\text { GO: } 0065007 \text {, biological regulation; GO: } 0009987 \text {, cellular process; GO: } 0051179 \text {, } \\
\text { localization; GO: 0008152, metabolic process; GO:0032502, developmental process; } \\
\text { GO:0051704, multi-organism process; GO:0032501, multicellular organismal process; } \\
\text { GO:0000003, reproduction; GO: 0022414, reproductive process; GO:0050896; response to } \\
\text { stimulus; GO:0023052, signalling }\end{array}$ & $\begin{array}{l}\text { GO:000548, binding; G0:0003824, } \\
\text { catalytic activity; GO:0005215, } \\
\text { transporter activity; GO:0005198, } \\
\text { structural molecule activity; } \\
\text { GO:0098772, molecular function } \\
\text { regulator }\end{array}$ \\
\hline
\end{tabular}

\section{Discussion}

The seroprevalence estimate obtained for the three infections were higher than observed in previous studies. In particular, the presence of PrV (48.9\%) in our population, is higher than reported in the same area by Bertelloni et al. (2020) ${ }^{42}(28.6 \%)$ and in previous studies conducted in North-West Italy, indicating the importance of this animal species in the endemicity of Aujeszky's disease ${ }^{27}$. The seroprevalence of PrV in wild boar has been already described in many European countries (France, Germany, Spain, Slovenia, Croatia, and Czech Republic) ranging from 4-66\%26,28,43-47.

This investigation, point out also a higher seroprevalence of Brucella than reported in other studies carried out in past years in Italy $\left(0.00 \%{ }^{48} ; 0.53 \% 42\right.$, as well as for Leptospira in Italy $\left(6.0 \%{ }^{48} ; 15.3 \%{ }^{49} ; 9.5 \%, 8.8 \%{ }^{42}\right)$ and in Europe $\left(3.1 \%^{17} ; 10.4 \%^{19}\right)$.

The results of the GWAS suggest that some genes might have a role in the resistance/susceptibility to the studied bacterial and viral diseases in wild boar, but no gene was found common to the three infections. 
The genomic windows $250 \mathrm{Kbp}$ downstream and upstream to the significant SNPs contained a variable number of genes, ranged from 9 (Pseudorabies) to 20 (Leptospira), as reported in Table 3. Interesting is that several SNPs are close to each other, suggesting to be in linkage disequilibrium and probably fixed. Two couple of SNPs were nearby found in Brucella infection, ALGA0073505 - WU_10.2_13_200912860 ( 182 Kbp of distance) and MARC0024545 ALGA0072626 ( $26 \mathrm{Kbp}$ of distance). The closest SNPs are H3GA0042130 with ASGA0066225, identified in Leptospira analysis, where markers are distant less than $15 \mathrm{Kbp}$.

On chromosome 12, seven genes associated with Pseudorabies and involved in multiple biological processes are located. For instance, the MGAT5B gene (alpha-1,6-mannosylglycoprotein 6-beta-N-acetylglucosaminyltransferase B) is related to the Golgi. The Golgi apparatus operates at the intersection of the secretory, lysosomal, and endocytic pathways. Several studies ${ }^{50,51}$ have indicated that viral PrV envelopment and tegumentation occurs at late Golgi or post-Golgi compartments, suggesting that this gene may have a role in PrV virulence and dissemination. As previously reported (Figure 4a), this gene is linked to other two gene of interest, the JMJD6 (JmjC domain-containing protein) and the METTL23 (methyltransferase like 23) genes. The JMJD6 gene has many functions, ranging from a cell surface receptor for recognition of apoptotic cells to a nuclear factor responsible for lysine hydroxylation and arginine demethylation ${ }^{52}$. Recent reports indicating a multifactorial role in foot-and-mouth disease virus (FMDV) infection ${ }^{53}$, in tumorigenesis and virological interactions ${ }^{54}$. METTL23 belongs to a family of methyltransferase like proteins (METTL) that transfer methyl group to various substrates and it is involved in human intellectual disability ${ }^{55}$. The same functionality has been attributed to the MFSD11 (major facilitator superfamily domain containing 11) gene $e^{56}$.

On the same chromosome SEC14L 1 gene was interestingly detected (SEC14 like lipid binding, also called PRELID4A), it interacts with RIG-I, a cytosolic pattern recognition receptor, which has found to be required for the activation of anti-PrV activity ${ }^{57}$.

MXRA7 (matrix remodelling associated 7) is highly expressed in murine and human ocular tissues and might play a role in pathological processes or diseases involving injury, neovascularization and would healing ${ }^{58}$. Another study ${ }^{59}$ report evidence for a protective role in the mouse psoriatic epidermis. Moreover, MXRA7 gene might be involved in bone marrow mesenchymal stem cells (BMSCs) functions ${ }^{60}$.

SRSF2 (serine and arginine rich splicing factor 2; also known as SFRS2) gene plays vital roles in a number of biological and pathological processes and it is associated in humans with the progression of a variety of diseases, including viral infection and tumorigenesis ${ }^{61}$.

On chromosome 18, CFTR (Cystic fibrosis transmembrane conductance regulator) and CTTNBP2 (cortactin binding protein 2) genes were detected. Interesting the role of CTTNBP2 in cattle and humans. In the Brown Swiss cattle breed this gene is involved in a recessive neurological disease ${ }^{62}$, the Bovine Progressive Degenerative Myeloencephalopathy (Weaver Syndrome). It is considered as a good candidate gene in humans for a role in the pathogenesis of mental retardation ${ }^{63}$ such as autism-like behaviours ${ }^{64}$.

Genes linked to nervous system are probable and expected to be found, because neurological signs predominate with Pseudorabies disease progression, e.g. ataxia, circling, paresis and paralysis ${ }^{65}$.

Several genes associated with host resistance or susceptibility to Brucella spp. have been identified in cattle $e^{66}$, buffalo ${ }^{67}$, goats ${ }^{68,69}$, humans and Sus Scrofa ${ }^{70}$, from those, also different type of Collagenases. In this research the Collagen type VIII Alpha 1 chain is identified, i.e. COL8A1. COL28A1 has been previously associated with antibody response in feral swine (Sus scrofa) infected with Brucella suis ${ }^{70}$, suggesting that $C O L 8 A 1$ may plays an analogue role in wild board.

Genes implicated in viral infections are $M X 1$ (Interferon-induced GTP-binding protein Mx1) and MX2 (Interferon-induced GTP-binding protein Mx2) ${ }^{71}$. Mx proteins are interferon (IFN)-induced dynamin-like GTPases that are present in all vertebrates and are known to inhibit the multiplication of several viruses $^{72}$, including vesicular stomatitis virus $(\mathrm{VSV})^{73}$, influenza A virus (FLUAV) ${ }^{74}$ and classical swine fever virus $(\mathrm{CSFV})^{75-77}$. Furthermore, recent studies have shown that MX1 inhibits the replication of foot-and-mouth disease virus (FMDV) (as JMJD6 found associated with Pseudorabies), and bovine viral diarrhoea virus (BVDV) ${ }^{78}$. Finally, porcine $M X 2$ was also found to have the antiviral activity against Porcine reproductive and respiratory syndrome virus $\left(\right.$ PRRSV) ${ }^{79}$.

As STRING software highlighted, the Mx genes are flanked by the BACE2, the TMPRSS2, the FAM3B and RIPKA genes. The TMPRSS2 (transmembrane serine protease 2) gene encodes a serine protease that can process the influenza A virus hemagglutinin into its fusion-competent state in human airway epithelial cells ${ }^{80}$ and is mainly involved in SARS-CoV and SARS-CoV-2 infections ${ }^{81}$.

The second cluster that STRING identified for Brucella, was formed by CMSS1 and FILIP1L genes, but no studies are found describing these two genes.

NTM (Neurotrimin) gene encodes a member of the IgLON (LAMP, OBCAM, NTM) family of immunoglobulin (Ig) domain-containing

glycosylphosphatidylinositol (GPI)-anchored cell adhesion molecules. The study performed in humans suggested that NTM gene is associated with the level of the intelligence quotient (IQ) and genome wide association studies identified an association between NTM variation and cognitive function performances in humans 82,83 .

Among the genes here highlighted associated with Leptospira desease, several of them are previously found to be associated with human neurological disorders: IMPA2, GNAL, MPPE1 and AFG3L2. IMPA2 (CIDE-N domain-containing protein) gene has been associated with bipolar disorder, schizophrenia ${ }^{84}$ and febrile seizure ${ }^{74}$ (Nakayama et al. 2004). GNAL (G protein subunit alpha L) gene has been linked to bipolar disorder and schizophrenia ${ }^{85}$. MPPE1

Page 6/16 
(Metallophosphoesterase 1) is clustered with IMPA2 and GNAL genes through STRING software (Figure 4c). Dysregulation of protein phosphorylation and subsequent abnormal cellular signalling has been postulated to be involved in neuropsychiatric disorders, thus making MPPE1 a plausible biological candidate gene for bipolar disorder (BPD) ${ }^{86}$. AFG3L2 (AFG3 Like Matrix AAA Peptidase Subunit 2) gene is a candidate gene for hereditary spastic paraplegias or neurodegenerative disorders (https://www.genecards.org/).

These results are interesting because human patients affected from Leptospira reported neurological manifestations in only $10-15 \%$ of cases ${ }^{87}$. The associations here identified, suggest that nervous system could be more involved in wild board Leptospira infections.

Another interesting gene is SPIRE1 (KIND domain-containing protein) which belongs to the SPIRE family that has emerged as a class of host cell factors that may affect the invasion process. Interestingly, SPIRE1 has been implicated in the infection of Salmonella Typhimurium ${ }^{88}$.

Other two genes of interest are the PRELID3A (PRELI/MSF1 domain-containing protein, also called SLMO1) and TUBB6 (Tubulin Beta 6 Class V). In particular, the PRELI-like family proteins acted as lipid transporters and play an important role of embryonic and development lymphocyte differentiation. The PRELI-like family proteins have been proposed to involve many cellular functions including apoptosis, cellular lipid metabolism and cellular signalling and were correlated with several types of diseases and malignant tumours ${ }^{89}$.

TUBB6 gene was found associated with muscle differentiation and regeneration ${ }^{90}$. In mouse, CIDEA (Cell Death Inducing DFFA Like Effector A) gene regulates thermogenesis, lipolysis, and conservation of energy and it is considered to be a proapoptotic factor ${ }^{91}$. The $S H 3 P X D 2 A$ gene was studied in mouse and humans defining it as a potential risk gene for orofacial clefting, indeed, Cejudo-Martin et al. (2014) $)^{92}$ argued that disruption of the mouse SH3PXD2A gene was associated with complete cleft of the secondary palate in $50-90 \%$ of mutant mice.

CALHM3 (Calcium Homeostasis Modulator 3) gene together with CALHM1, form a complex to mediate rapid taste neurotransmission, indeed, genetic deletion of CALHM3 abolished sweet, bitter, and human taste perception ${ }^{93}$. Also, NEURL 1 (neuralized E3 ubiquitin protein ligase 1) gene has many functions, in particularly it was related to the cellular process involved in reproduction in multicellular organism ${ }^{94}$. Moreover, NEURL 1 has been associated with fat content in Nordic cattle breeds ${ }^{95}$ while in humans this gene was related to survival in Oesophageal adenocarcinoma (EAC) patients ${ }^{71}$.

On the same chromosome we found PCGF6 (polycomb group ring finger 6) gene which plays an essential role in embryonic development of mice and in mouse fertility ${ }^{96}$.

In summary, significant SNPs were detected to be associated with viral and bacterial disease. Furthermore, among the 29 genes highlighted, 18 genes could be considered candidate genes for genetic resistance or susceptibility as they are implicated in viral (SEC14L 1, JMJD6, SRSF2, TMPRSS2, MX1, MX2) or bacterial (COL8A1, SPIRE1) infections, in neurological disorders (MFSD11, METTL23, CTTNBP2, BACE2, IMPA2, MPPE1 and GNAL) that is in line with Pseudorabies and Leptospira symptoms, or in the functions of the Golgi complex (MGAT5B), organelle where viral envelope is occurred. Results presented here represent interesting areas for future research, validation studies and fine mapping of candidate genes involved in bacterial and viral infections in wild boar.

\section{Methods}

\section{Statement of Animal Rights}

The wild boar were not hunted for the purpose of this study and that none of the authors were involved with the hunting. Animals were hunted following regional hunting laws (Regolamento di attuazione della legge regionale 12 gennaio 1994 n 3 DPGR 48/R/2017). Thus, in accordance to the 2010/63/EU guide and the adoption of the Law D.L. 04/03/2014, n.26 by the Italian Government, an ethical approval was not required for this study.

\section{Sample Collection}

96 wild boars (54 females and 42 males) hunted in Tuscany during the 2018-2019 and 2019-2020 hunting seasons (from November to January) were sampled. The study was part of the project PRA_2018_56 financed by University of Pisa and entitled "Evaluation of hygienic-sanitary and qualitative parameters of wild boars hunted in Tuscany and Liguria" 14,29,42, which had the purpose to investigate the role of the wild boar in the epidemiology of some infectious diseases for livestock and humans.

Animals were hunted in different areas in the provinces of Pisa (34, from 5 different localities), Siena (20, from 2 localities), Grosseto (35, from 11 localities), and Livorno (7, from 5 localities), characterised by the abundant presence of wild boar and other wild ungulates ${ }^{97}$. At postmortem examination, samples did not present relevant lesions related to infectious disease. During necroscopy, the kidneys were collected, and serum was extracted from the infraorbital cavities ${ }^{98}$.

\section{Serological Analysis for Pseudorabies, Brucella and Leptospira infections}

Serum samples were analysed by ID Screen Aujeszky gB competitive kit detecting anti-gB PrV antibodies (ID.vet, Grabels, France). Test procedures and interpretation of results were performed according to the manufacturer's instructions, adopting the short serum incubation protocol. The optical density was measured by a plate reader (Multiscan FC; Thermo Scientific, Waltham, MA, USA) at 450 nm wave-length. 
Rose Bengal Test (RBT) and complement fixation test (CFT) were employed to detect anti-brucella antibodies. RBT and CFT were performed as described by World Organization for Animal Health (OIE) (OIE 2016); antigens used in both tests were obtained from the "Istituto Zooprofilattico Sperimentale dell'Abruzzo e del Molise G. Caporale, Teramo."

Leptospira antibodies were detected by microscopic agglutination test (MAT) as previously described ${ }^{11}$, titers of 1:100 were considered positive. The serovars were employed as live antigens in MAT (Supplementary Information). As positive control has been used anti-serum for each investigated serogroup provided by "Istituto Zooprofilattico Sperimentale della Lombardia ed Emilia Romagna, Brescia," while sterilized saline water was used as a negative control.

\section{DNA extraction and SNPs quality control (QC)}

Ninety-six wild boars were genotyped using the "Geneseek Genomic Profiler Porcine HD (70k)", containing 62,330 SNPs. SNP genotyping was outsourced at the Science and Technology Park of Sardinia (Porto Conte Ricerche; https://www.portocontericerche.it/it).

Total DNA extraction for each sample of kidney was performed, starting from about 100 microliters of homogenised tissue, according to the salting out procedure proposed by Armani et al. $(2011)^{99}$, further modified and applied as Salting out reference protocol by Armani et al. (2014) ${ }^{100}$. Final DNA concentration and purity were assessed with Nanodrop ND-1000 spectrophotometer (NanoDrop Technologies, Wilmington, DE, US) by two subsequent measurements of the absorbance value at $260 \mathrm{~nm}$ and calculation of A260/A280 and of A260/230 ratios. 260/280 and 260/230 values $\geq 2$ were considered indicative of nucleic acid purity according to the manufacturer's indications (https://tools.thermofisher.com/content/sfs/brochures/TN52646E-0215M-NucleicAcid.pdf). DNA samples were prepared in a volume of 30 ul per concentration of 50ng/ul in 96 plates and sent to the laboratory for genotyping.

The SNPs quality control (QC) has performed with PLINK v.1.07 (http://zzz.bwh.harvard.edu/plink/) and only autosomal SNPs with a call rate higher than $95 \%$, a minor allele frequency (MAF) $>1 \%$ and with no extreme deviation from Hardy-Weinberg equilibrium (P value $>0.00001)$, were included in the analysis. After QC, 42,431 SNPs mapped on the 18 porcine autosomes and 93 individuals, were retained. The number of SNPs for chromosome is reported in Table 1.

\section{Genome wide association study and Gene set enrichment analysis}

The association analysis was performed with GenABEL ${ }^{101}$, which performs a simple linear regression marker-phenotype analysis. Firstly, the genomic relationship matrix was calculated with the function ibs (https://rdrr.io/cran/GenABEL/man/ibs.html), where for a given pair of individuals i and j, the identical by state coefficients $\left(f_{i, j}\right)$ is calculated as follows:

$$
f_{i, j}=\frac{1}{N} \sum k \frac{\left(x_{i, k}-p_{k}\right)\left(x_{i, k}-p_{k}\right)}{p_{k}\left(1-p_{k}\right)}
$$

where $N$ is the number of markers used, $x_{i, k}$ is the genotype of the $i^{\text {th }}$ individual at the $k^{\text {th }}$ SNP (coded as $0,1 / 2$ and 1 ), $p_{\mathrm{k}}$ is the frequency of the " + " allele and $\mathrm{k}=1, \ldots, \mathrm{N}$.

Then, the additive polygenic model described above was applied:

$$
Y=X \beta+a+e
$$

Each phenotype has been analysed separately (affected: Pseudorabies 42; Leptospira 31; Brucella 15); $\beta$ was a vector with the fixed sex effect and $\mathbf{X}$ was the incidence matrix that associated each observation to levels of factor in $\beta$. The random effects in the model were the animal and the residual, which were assumed normally distributed as $\mathbf{\alpha} \sim \mathrm{N}\left(0, G \sigma_{g}^{2}\right)$ and $\mathrm{e} \sim \mathrm{N}\left(0, I \sigma_{e}^{2}\right)$, where $\mathbf{G}$ was the genomic relationship matrix, I is an identity matrix, and $\sigma_{g}^{2}$ and $\sigma_{e}^{2}$ are the additive genomic and residual variances, respectively. Regression was performed using the GenABEL function mmscore and the associations between marker and phenotype with a $P$ value $\leq 5 \times 10^{-5}$ were considered significant ${ }^{102}$. For each trait, a Manhattan plot was produced using the $\mathrm{R}$ software ${ }^{103}$.

VeP database (https://www.ensembl.org/info/docs/tools/vep/index.html) was used to upload chromosome position from Sus Scrofa 10.2 assembly (https://may2017.archive.ensembl.org/Sus_scrofa/Info/Index) to the more recent Sus Scrofa 11.1 (https://www.ensembl.org/Sus_scrofa/Info/Annotation), and to investigate the type of significant SNPs. A genomic window of $250 \mathrm{Kbp}$ upstream and downstream from the significant SNP for each trait was investigated using the R package biomaRt ${ }^{103,104}$, which accesses the data available in Ensembl database (https://www.ensembl.org). The genes identification was based on Scrofa 11.1 assembly (https://www.ensembl.org/Sus_scrofa/Info/Annotation). For the Gene set enrichment analysis, the lists of protein coding genes were uploaded to STRING $11.5^{105}$ and PANTHER v. $16.0^{106}$. 


\section{Declarations}

\section{Acknowledgements}

Authors acknowledge University of Pisa to provide the data.

\section{Author contributions statement}

MCF performed the formal analysis and wrote the original draft. AC reviewed the manuscript and supervised. FF reviewed the manuscript and funding acquisition; LT, FB, AA, FF, MM found resources and reviewed the manuscript. RB conceptualized and reviewed the manuscript. FC elaborated the methodology and wrote the original draft.

\section{Competing interests}

The authors declare they do not have any competing interests.

\section{Data availability}

The datasets analyzed during the current study are available online on the following link: https://osf.io/bz89n/.

\section{Funding}

This work was supported by grants of the University of Pisa (PRA 2018_56).

\section{References}

1. Choi, S. K. et al. Asia-wide phylogeography of wild boar (Sus scrofa) based on mitochondrial DNA and Y-chromosome: Revising the migration routes of wild boar in Asia. PLOS ONE 15, e0238049 (2020).

2. Putman, R., Apollonio, M. \& Andersen, R. Ungulate Management in Europe: Problems and Practices. (Cambridge University Press, 2011).

3. Massei, G. et al. Wild boar populations up, numbers of hunters down? A review of trends and implications for Europe. Pest Manag. Sci. 71, 492-500 (2015).

4. Pittiglio, C., Khomenko, S. \& Beltran-Alcrudo, D. Wild boar mapping using population-density statistics: From polygons to high resolution raster maps PLOS ONE 13, e0193295 (2018).

5. Santilli, F. \& Varuzza, P. Factors affecting wild boar ( Sus scrofa ) abundance in southern Tuscany. Hystrix Ital. J. Mammal. 24, 169-173 (2013).

6. Lombardini, M., Meriggi, A. \& Fozzi, A. Factors influencing wild boar damage to agricultural crops in Sardinia (Italy). Curr. Zool. 63, 507-514 (2017).

7. Blanchong, J. A., Robinson, S. J., Samuel, M. D. \& Foster, J. T. Application of genetics and genomics to wildlife epidemiology. J. Wildl. Manag. 80, 593-608 (2016).

8. Olsen, S. C. \& Tatum, F. M. Swine brucellosis: current perspectives. Vet. Med. Auckl. NZ 8, 1-12 (2017).

9. Díaz Aparicio, E. Epidemiology of brucellosis in domestic animals caused by Brucella melitensis, Brucella suis and Brucella abortus. Rev. Sci. Tech. Off. Int. Épizooties 32, (2013).

10. Cilia, G. et al. Genital Brucella suis Biovar 2 Infection of Wild Boar (Sus scrofa) Hunted in Tuscany (Italy). Microorganisms $\mathbf{9}, 582$ (2021).

11. Bertelloni, F. et al. Serological survey on Leptospira infection in slaughtered swine in North-Central Italy. Epidemiol. Infect. 146, 1275-1280 (2018)

12. Fretin, D. et al. Unexpected Brucella suis Biovar 2 Infection in a Dairy Cow, Belgium. Emerg. Infect. Dis. 19, 2053-2054 (2013).

13. Szulowski, K., Iwaniak, W., Weiner, M. \& Złotnicka, J. Brucella suis biovar 2 isolations from cattle in Poland. Ann. Agric. Environ. Med. AAEM 20, 672675 (2013).

14. Cilia, G., Bertelloni, F., Angelini, M., Cerri, D. \& Fratini, F. Leptospira Survey in Wild Boar (Sus scrofa) Hunted in Tuscany, Central Italy. Pathogens 9 , 377 (2020).

15. Adler, B. \& de la Peña Moctezuma, A. Leptospira and leptospirosis. Vet. Microbiol. 140, 287-296 (2010).

16. Ellis, W. A. Animal Leptospirosis. in Leptospira and Leptospirosis (ed. Adler, B.) 99-137 (Springer, 2015). doi:10.1007/978-3-662-45059-8_6.

17. Boqvist, S., Bergström, K. \& Magnusson, U. Prevalence of Antibody to Six Leptospira Servovars in Swedish Wild Boars. J. Wildl. Dis. 48, $492-496$ (2012).

18. Vale-Gonçalves, H. M. et al. Prevalence of Leptospira antibodies in wild boars (Sus scrofa) from Northern Portugal: risk factor analysis. Epidemiol. Infect. 143, 2126-2130 (2015).

19. Żmudzki, J. et al. First overall report of Leptospira infections in wild boars in Poland. Acta Vet. Scand. 58, 3 (2016).

20. Ebani, V., Bertelloni, F., Pinzauti, P. \& Cerri, D. Seroprevalence of Leptospira spp. and Borrelia burgdorferi sensu Lato in Italian horses. Ann. Agric. Environ. Med. AAEM 19, 237-40 (2012).

21. Fratini, F. et al. The presence of leptospira in coypus (Myocastor coypus) and rats (Rattus norvegicus) living in a protected wetland in Tuscany (Italy). Vet. Arh. 85, 407-414 (2015). 
22. Fratini, F. Leptospira infection in wild animals. https://onesearch.unipi.it.

23. Mettenleiter, T. C. Aujeszky's disease (pseudorabies) virus: the virus and molecular pathogenesis-state of the art, June 1999. Vet. Res. 31, 99-115 (2000).

24. Boadella, M., Gortázar, C., Vicente, J. \& Ruiz-Fons, F. Wild boar: an increasing concern for Aujeszky's disease control in pigs? BMC Vet. Res. 8, 7 (2012).

25. Ruiz-Fons, F., Segalés, J. \& Gortázar, C. A review of viral diseases of the European wild boar: effects of population dynamics and reservoir rôle. Vet. J. Lond. Engl. 1997176, 158-169 (2008).

26. Müller, T. et al. Characterization of pseudorabies virus of wild boar origin from Europe. Epidemiol. Infect. 138, 1590-1600 (2010).

27. Verin, R., Varuzza, P., Mazzei, M. \& Poli, A. Serologic, molecular, and pathologic survey of pseudorabies virus infection in hunted wild boars (Sus scrofa) in Italy. J. Wildl. Dis. 50, 559-565 (2014).

28. Moreno, A. et al. Detection and molecular analysis of Pseudorabies virus strains isolated from dogs and a wild boar in Italy. Vet. Microbiol. 177, 359365 (2015).

29. Pacini, M. I. et al. Detection of Pseudorabies Virus in Wild Boar Foetus. Anim. Open Access J. MDPI 10, 366 (2020).

30. Reiner, G. Investigations on genetic disease resistance in swine-A contribution to the reduction of pain, suffering and damage in farm animals. Appl. Anim. Behav. Sci. (2009).

31. Spielman, D., Brook, B. W., Briscoe, D. A. \& Frankham, R. Does Inbreeding and Loss of Genetic Diversity Decrease Disease Resistance? Conserv. Genet. 5, 439-448 (2004).

32. Whiteman, N. K., Matson, K. D., Bollmer, J. L. \& Parker, P. G. Disease ecology in the Galápagos Hawk (Buteo galapagoensis): host genetic diversity, parasite load and natural antibodies. Proc. R. Soc. B Biol. Sci. 273, 797-804 (2006).

33. Coltman, D. W., Pilkington, J. G., Smith, J. A. \& Pemberton, josephine M. Parasite-Mediated Selection Against Inbred Soay Sheep in a Free-Living Island Populaton. Evolution 53, 1259-1267 (1999).

34. Cassinello, J., Gomendio, M. \& Roldan, E. R. S. Relationship between Coefficient of Inbreeding and Parasite Burden in Endangered Gazelles. Conserv. Biol. 15, 1171-1174 (2001).

35. Acevedo-Whitehouse, K., Gulland, F., Greig, D. \& Amos, W. Disease susceptibility in California sea lions. Nature 422, 35-35 (2003).

36. Acevedo-Whitehouse, K. et al. Genetic resistance to bovine tuberculosis in the Iberian wild boar. Mol. Ecol. 14, 3209-3217 (2005).

37. Bernatchez, L. \& Landry, C. MHC studies in nonmodel vertebrates: what have we learned about natural selection in 15 years? J. Evol. Biol. 16, 363377 (2003).

38. Acevedo-Whitehouse, K. \& Cunningham, A. A. Is MHC enough for understanding wildlife immunogenetics? Trends Ecol. Evol. 21, 433-438 (2006).

39. Queirós, J., Alves, P. C., Vicente, J., Gortázar, C. \& de la Fuente, J. Genome-wide associations identify novel candidate loci associated with genetic susceptibility to tuberculosis in wild boar. Sci. Rep. 8, 1980 (2018).

40. Bai, X. et al. Investigating the genetic architecture of disease resilience in pigs by genome-wide association studies of complete blood count traits collected from a natural disease challenge model. BMC Genomics 22, 535 (2021).

41. Uemoto, Y. et al. Genome-wide association studies for production, respiratory disease, and immune-related traits in Landrace pigs. Sci. Rep. 11, 15823 (2021).

42. Bertelloni, F. et al. Serological Survey on Bacterial and Viral Pathogens in Wild Boars Hunted in Tuscany. EcoHealth 17, 85-93 (2020).

43. Vicente, J. et al. Antibodies to selected viral and bacterial pathogens in European wild boars from southcentral Spain. J. Wildl. Dis. 38, 649-652 (2002)

44. Sedlak, K., Bartova, E. \& Machova, J. Antibodies to selected viral disease agents in wild boars from the Czech Republic. J. Wildl. Dis. 44, 777-780 (2008).

45. Vengust, G., Lindtner-Knific, R., Zele, D. \& Bidovec, A. Leptospira antibodies in wild boars (Sus scrofa) in Slovenia. Eur. J. Wildl. Res. 54, 749-752 (2008).

46. Cano-Manuel, F. J. et al. Long-term monitoring of 10 selected pathogens in wild boar (Sus scrofa) in Sierra Nevada National Park, southern Spain. Vet. Microbiol. 174, 148-154 (2014).

47. Caruso, C. et al. Serological and virological survey of hepatitis E virus in wild boar populations in northwestern Italy: detection of HEV subtypes $3 \mathrm{e}$ and 3f. Arch. Virol. 160, 153-160 (2015).

48. Ebani, V. V., Cerri, D., Poli, A. \& Andreani, E. Prevalence of Leptospira and Brucella Antibodies in Wild Boars (Sus scrofa) in Tuscany, Italy. J. Wildl. Dis. 39, 718-722 (2003).

49. Chiari, M. et al. Seroprevalence and risk factors of leptospirosis in wild boars ( Sus scrofa ) in northern Italy. Hystrix Ital. J. Mammal. 27, 145-149 (2016).

50. Omar, O. S., Simmons, A. J., Andre, N. M., Wilson, D. W. \& Gross, S. T. Pseudorabies virus and herpes simplex virus type 1 utilize different tegumentglycoprotein interactions to mediate the process of envelopment. Intervirology 56, 50-54 (2013).

51. Nanbo, A., Noda, T. \& Ohba, Y. Epstein-Barr Virus Acquires Its Final Envelope on Intracellular Compartments With Golgi Markers. Front. Microbiol. 9, 454 (2018). 
52. Chang, B., Chen, Y., Zhao, Y. \& Bruick, R. K. JMJD6 Is a Histone Arginine Demethylase. Science 318, 444-447 (2007).

53. Lawrence, P. \& Rieder, E. Insights into Jumonji C-domain containing protein 6 (JMJD6): a multifactorial role in foot-and-mouth disease virus replication in cells. Virus Genes 53, 340-351 (2017).

54. Vangimalla, S. S., Ganesan, M., Kharbanda, K. K. \& Osna, N. A. Bifunctional Enzyme JMJD6 Contributes to Multiple Disease Pathogenesis: New Twist on the Old Story. Biomolecules 7, 41 (2017).

55. Almannai, M. et al. Further delineation of METTL23-associated intellectual disability. Am. J. Med. Genet. A. 182, 785-791 (2020).

56. Anazi, S. et al. Expanding the genetic heterogeneity of intellectual disability. Hum. Genet. 136, 1419-1429 (2017).

57. Chen, X. et al. Pseudorabies virus UL24 antagonizes OASL-mediated antiviral effect. Virus Res. 295, 198276 (2021).

58. Jia, C., Zhang, F., Zhu, Y., Qi, X. \& Wang, Y. Public data mining plus domestic experimental study defined involvement of the old-yet-uncharacterized gene matrix-remodeling associated 7 (MXRA7) in physiopathology of the eye. Gene 632, 43-49 (2017).

59. Ning, J. et al. Altered expression of matrix remodelling associated 7 (MXRA7) in psoriatic epidermis: Evidence for a protective role in the psoriasis imiquimod mouse model. Exp. Dermatol. 27, 1038-1042 (2018).

60. Zhou, Z. et al. Matrix remodeling associated 7 promotes differentiation of bone marrow mesenchymal stem cells toward osteoblasts. J. Cell. Physiol. 234, 18053-18064 (2019).

61. Li, K. \& Wang, Z. Splicing factor SRSF2-centric gene regulation. Int. J. Biol. Sci. 17, 1708-1715 (2021).

62. McClure, M. et al. Fine mapping for Weaver syndrome in Brown Swiss cattle and the identification of 41 concordant mutations across NRCAM, PNPLA8 and CTTNBP2. PloS One 8, e59251 (2013).

63. Patel, C. et al. Translocation breakpoint at 7q31 associated with tics: further evidence for IMMP2L as a candidate gene for Tourette syndrome. Eur. J. Hum. Genet. 19, 634-639 (2011).

64. Shih, P.-Y. et al. CTTNBP2 Controls Synaptic Expression of Zinc-Related Autism-Associated Proteins and Regulates Synapse Formation and Autismlike Behaviors. Cell Rep. 31, 107700 (2020).

65. Sehl, J. \& Teifke, J. P. Comparative Pathology of Pseudorabies in Different Naturally and Experimentally Infected Species-A Review. Pathogens 9 , 633 (2020).

66. Yapan, S., Liping, S., Aizhen, G. \& Liguo, Y. Effects of toll-like receptor 2 gene mutation on resistance to bovine brucellosis. Livest. Sci. 170, 30-34 (2014).

67. Borriello, G. et al. Genetic Resistance to Brucella abortus in the Water Buffalo (Bubalus bubalis). Infect. Immun. 74, 2115-2120 (2006).

68. Rossi, U. A. et al. A haplotype at intron 8 of PTPRT gene is associated with resistance to Brucella infection in Argentinian creole goats. Vet. Microbiol. 207, 133-137 (2017).

69. Rossi, U. A. et al. Association of an IRF3 putative functional uORF variant with resistance to Brucella infection: A candidate gene based analysis of InDel polymorphisms in goats. Cytokine 115, 109-115 (2019).

70. Pierce, C. F. et al. Loci Associated With Antibody Response in Feral Swine (Sus scrofa) Infected With Brucella suis. Front. Vet. Sci. 7, 957 (2020).

71. Wang, Y., Liang, N., Xue, Z. \& Xue, X. Identifying an Eight-Gene Signature to Optimize Overall Survival Prediction of Esophageal Adenocarcinoma Using Bioinformatics Analysis of ceRNA Network. OncoTargets Ther. 13, 13041-13054 (2020).

72. Sasaki, K. et al. A single nucleotide polymorphism of porcine MX2 gene provides antiviral activity against vesicular stomatitis virus. Immunogenetics 66, 25-32 (2014).

73. Zhang, X. et al. In vitro inhibition of vesicular stomatitis virus replication by purified porcine Mx1 protein fused to HIV-1 Tat protein transduction domain (PTD). Antiviral Res. 99, 149-157 (2013).

74. Nakajima, E. et al. A Naturally Occurring Variant of Porcine Mx1 Associated with Increased Susceptibility to Influenza Virus In Vitro. Biochem. Genet. 45, 11-24 (2007).

75. Zhao, Y. et al. Human MxA protein inhibits the replication of classical swine fever virus. Virus Res. 156, 151-155 (2011).

76. He, D. et al. In vitro inhibition of the replication of classical swine fever virus by porcine Mx1 protein. Antiviral Res. 104, 128-135 (2014).

77. Zhou, J. et al. Porcine Mx1 Protein Inhibits Classical Swine Fever Virus Replication by Targeting Nonstructural Protein NS5B. J. Virol. 92, e02147-17 (2018).

78. Yuan, B., Fang, H., Shen, C. \& Zheng, C. Expression of porcine Mx1 with FMDV IRES enhances the antiviral activity against foot-and-mouth disease virus in PK-15 cells. Arch. Virol. 160, 1989-1999 (2015).

79. Wang, H. et al. The Interferon-Induced Mx2 Inhibits Porcine Reproductive and Respiratory Syndrome Virus Replication. J. Interferon Cytokine Res. Off. J. Int. Soc. Interferon Cytokine Res. 36, 129-139 (2016).

80. Böttcher, E. et al. Proteolytic Activation of Influenza Viruses by Serine Proteases TMPRSS2 and HAT from Human Airway Epithelium. J. Virol. 80, 9896-9898 (2006).

81. Bovo, S. et al. Describing variability in pig genes involved in coronavirus infections for a One Health perspective in conservation of animal genetic resources. Sci. Rep. 11, 3359 (2021).

82. Pan, Y., Wang, K.-S. \& Aragam, N. NTM and NR3C2 polymorphisms influencing intelligence: Family-based association studies. Prog. Neuropsychopharmacol. Biol. Psychiatry 35, 154-160 (2011).

Page 11/16 
83. Liu, F. et al. A Genomewide Screen for Late-Onset Alzheimer Disease in a Genetically Isolated Dutch Population. Am. J. Hum. Genet. 81, 17-31 (2007).

84. Yoshikawa, T. et al. Evidence for association of the myo-inositol monophosphatase 2 (IMPA2) gene with schizophrenia in Japanese samples. Mol. Psychiatry 6, 202-210 (2001).

85. Vuoristo, J. T. et al. Sequence and genomic organization of the human G-protein Golfa gene (GNAL) on chromosome 18p11, a susceptibility region for bipolar disorder and schizophrenia. Mol. Psychiatry 5, 495-501 (2000).

86. Lohoff, F. W., Ferraro, T. N., Brodkin, E. S., Weller, A. E. \& Bloch, P. J. Association between polymorphisms in the metallophosphoesterase (MPPE1) gene and bipolar disorder. Am. J. Med. Genet. B Neuropsychiatr. Genet. 153B, 830-836 (2010).

87. Mathew, T. et al. Neuroleptospirosis - revisited: experience from a tertiary care neurological centre from south India. Indian J. Med. Res. 124, 155-162 (2006).

88. Andritschke, D. et al. A Genome-Wide siRNA Screen Implicates Spire1/2 in SipA-Driven Salmonella Typhimurium Host Cell Invasion. PLOS ONE 11, e0161965 (2016).

89. Zhu, Y. et al. Lipid metabolism-related proteins of relevant evolutionary and lymphoid interest (PRELI) domain containing family proteins in cancer. Am. J. Transl. Res. 12, 6015-6026 (2020).

90. Randazzo, D. et al. Persistent upregulation of the $\beta$-tubulin tubb6, linked to muscle regeneration, is a source of microtubule disorganization in dystrophic muscle. Hum. Mol. Genet. 28, 1117-1135 (2019).

91. Viswakarma, N. et al. Transcriptional regulation of Cidea, mitochondrial cell death-inducing DNA fragmentation factor alpha-like effector A, in mouse liver by peroxisome proliferator-activated receptor alpha and gamma. J. Biol. Chem. 282, 18613-18624 (2007).

92. Cejudo-Martin, P. et al. Genetic Disruption of the Sh3pxd2a Gene Reveals an Essential Role in Mouse Development and the Existence of a Novel Isoform of Tks5. PLOS ONE 9, e107674 (2014).

93. Ma, Z. et al. CALHM3 Is Essential for Rapid Ion Channel-Mediated Purinergic Neurotransmission of GPCR-Mediated Tastes. Neuron 98, 547-561.e10 (2018).

94. Sadowska, A. et al. Transcriptional profiling of porcine granulosa cells exposed to 2,3,7,8-tetrachlorodibenzo-p-dioxin. Chemosphere 178, 368-377 (2017)

95. Iso-Touru, T., Sahana, G., Guldbrandtsen, B., Lund, M. S. \& Vilkki, J. Genome-wide association analysis of milk yield traits in Nordic Red Cattle using imputed whole genome sequence variants. BMC Genet. 17, 55 (2016).

96. Liu, M. et al. The polycomb group protein PCGF6 mediates germline gene silencing by recruiting histone-modifying proteins to target gene promoters. J. Biol. Chem. 295, 9712-9724 (2020).

97. Banca Dati Ungulati. Status, distribuzione, consistenza, gestione e prelievo venatorio delle popolazioni di Ungulati in Italia. Istituto Superiore per la Protezione e la Ricerca Ambientale https://www.isprambiente.gov.it/it/pubblicazioni/documenti-tecnici/banca-dati-ungulati-status-distribuzione.

98. Arenas-Montes, A. et al. Blood sampling by puncture in the cavernous sinus from hunted wild boar. Eur. J. Wildl. Res. 59, 299-303 (2013).

99. Armani, A., Castigliego, L., Tinacci, L., Gianfaldoni, D. \& Guidi, A. Molecular characterization of icefish, (Salangidae family), using direct sequencing of mitochondrial cytochrome b gene. Food Control 22, 888-895 (2011).

100. Andrea, A. et al. Development of a Simple and Cost-Effective Bead-Milling Method for DNA Extraction from Fish Muscles. Food Anal. Methods 7, 946-955 (2014).

101. Aulchenko, Y. S., Ripke, S., Isaacs, A. \& van Duijn, C. M. GenABEL: an R library for genome-wide association analysis. Bioinformatics 23, $1294-1296$ (2007).

102. Cecchi, F. et al. Genome scan for the possibility of identifying candidate resistance genes for goat lentiviral infections in the Italian Garfagnina goat breed. Trop. Anim. Health Prod. 51, 729-733 (2019).

103. Durinck, S. et al. BioMart and Bioconductor: a powerful link between biological databases and microarray data analysis. Bioinforma. Oxf. Engl. 21, 3439-40 (2005).

104. Durinck, S., Spellman, P. T., Birney, E. \& Huber, W. Mapping identifiers for the integration of genomic datasets with the R/Bioconductor package biomaRt. Nat. Protoc. 4, 1184-1191 (2009).

105. Szklarczyk, D. et al. The STRING database in 2017: quality-controlled protein-protein association networks, made broadly accessible. Nucleic Acids Res. 45, D362-D368 (2017).

106. Mi, H. et al. PANTHER version 16: a revised family classification, tree-based classification tool, enhancer regions and extensive API. Nucleic Acids Res. 49, D394-D403 (2021).

\section{Figures}




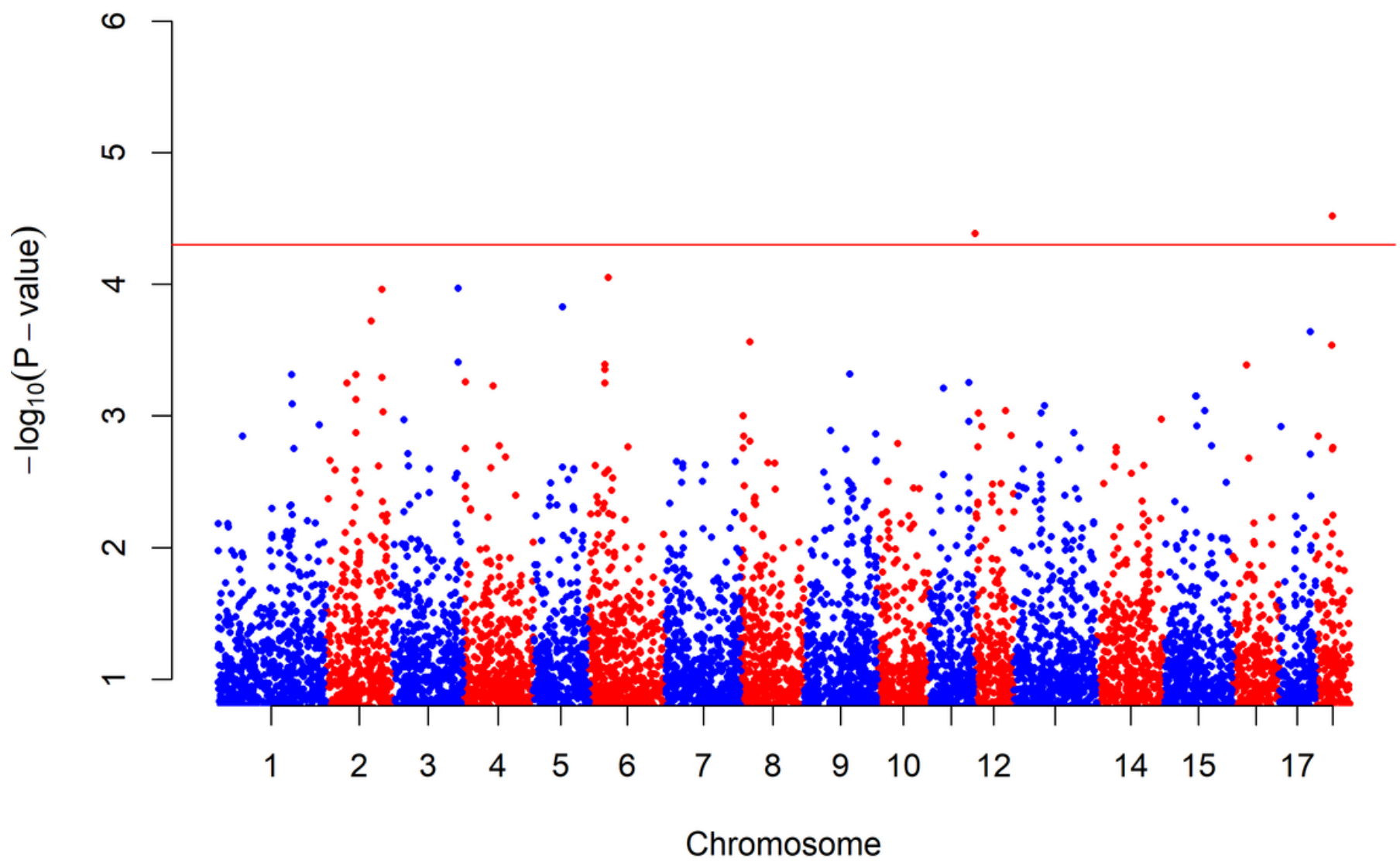

Figure 1

Manhattan plot of the test values obtained, for each marker for Pseudorabies virus. The horizontal red line separated the two most significant markers $(P<0.00005)$ 


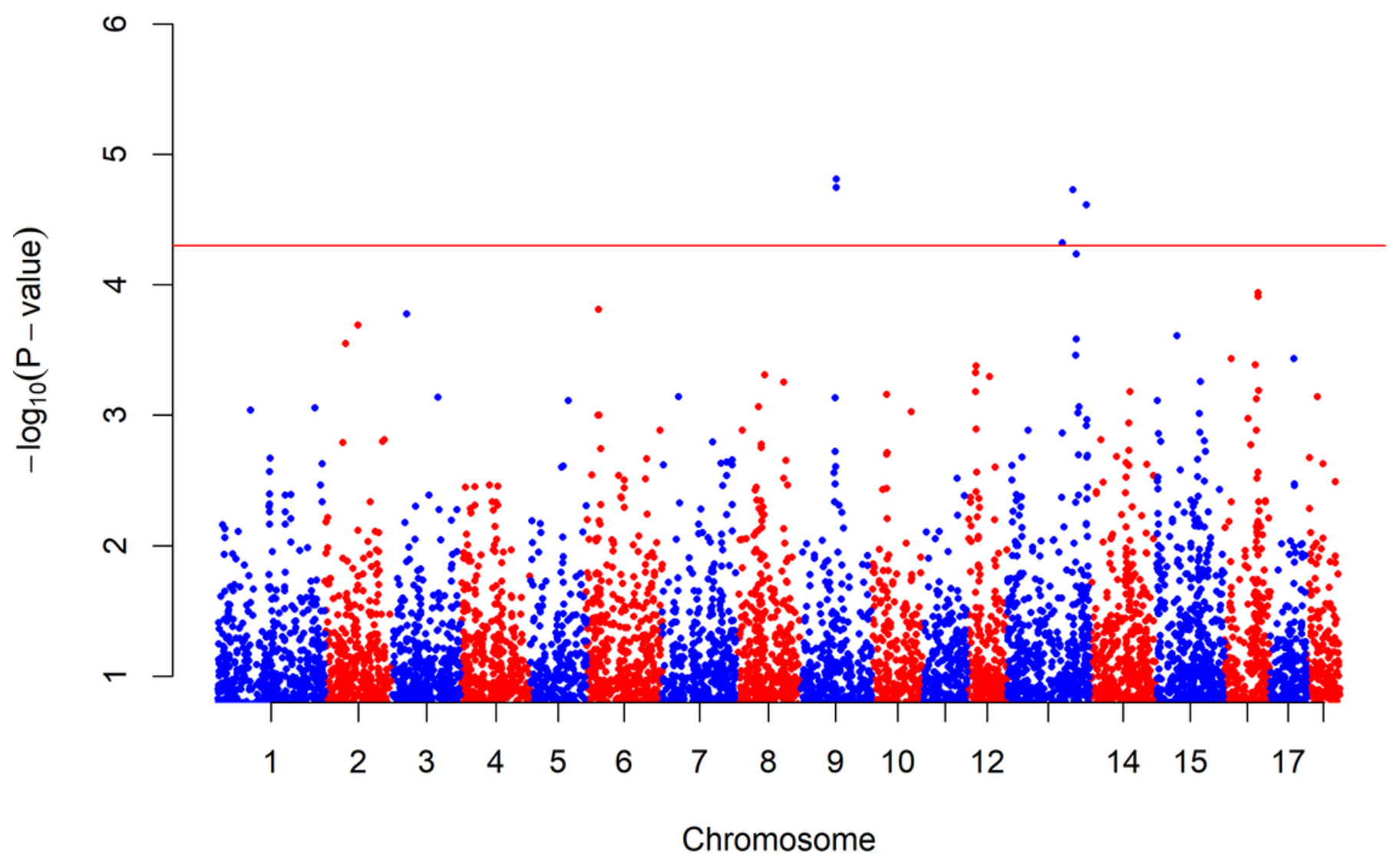

Figure 2

Manhattan plot of the test values obtained, for each marker for Brucella. The horizontal red line separated the seven most significant markers $(P<0.00005)$. SNPs ALGA0073505 and WU 10.213200912860 as SNPs MARC0024545 and ALGA0072626 on Chromosome 13 have an extremely closed position, difficult to spot the differences in the graph. 


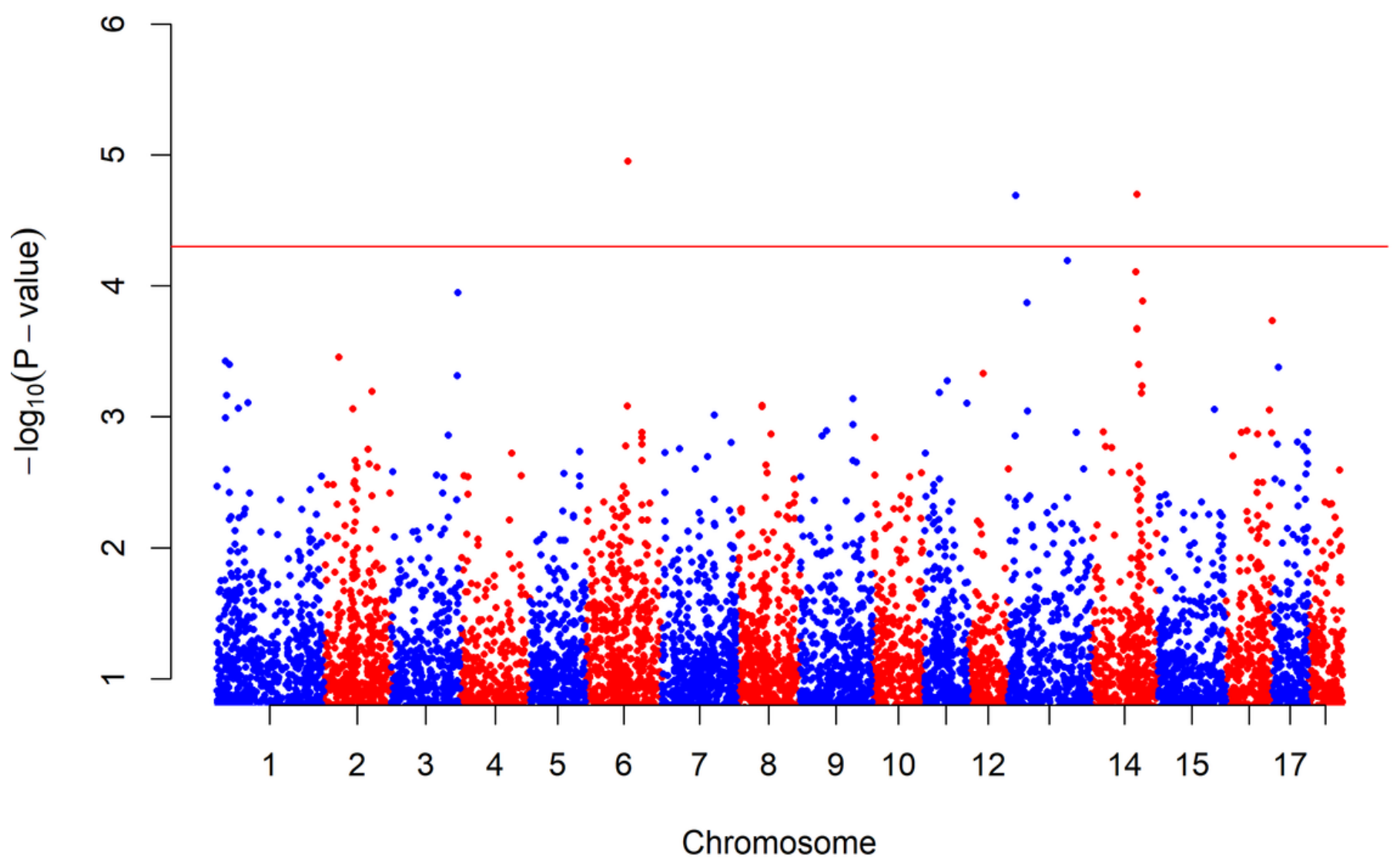

Figure 3

Manhattan plot of the test values obtained for Leptospira. The horizontal red line separated the four most significant markers $(P<0.00005)$. SNP H3GA0042130 and ASGA0066225 on Chromosome 14 have an extremely closed position, difficult to spot the differences in the graph. 
a)

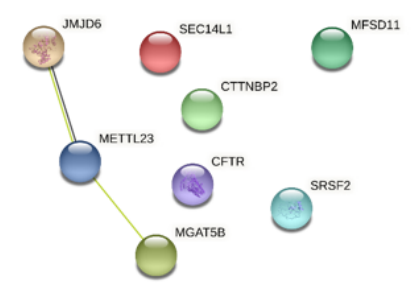

b)

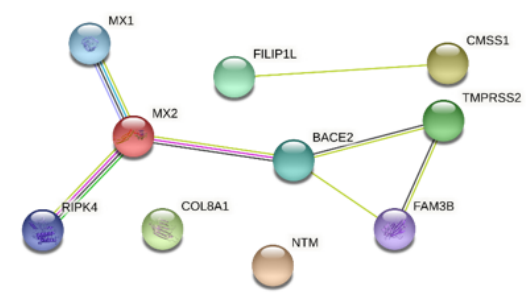

c)

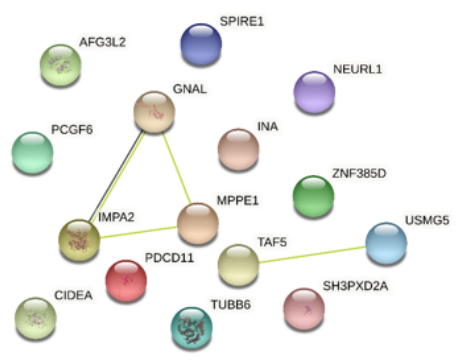

Figure 4

Protein networks of GWAS genes according to STRING database. a) Pseudorabies; b) Brucella; c) Leptospira. Nodes are proteins; lines indicate interactions between proteins with: pink lines for known interactions experimentally determined, sea blue for interactions derived by curated databases. For the predicted interactions, green is for neighbourhood gene, red lines for gene fusions and blue lines for gene co-occurrence. Black lines are for coexpression, light green lines for text mining and light blue lines for protein homology. Protein interactions include direct (physical) and indirect (functional) associations derived from different sources (genomic context, high through-put experiments, conserved co-expression, previous knowledge).

\section{Supplementary Files}

This is a list of supplementary files associated with this preprint. Click to download.

- Supplementarymatherials.docx 